\title{
PERAN DAN FUNGSI SOSIAL MASJID DALAM MENINGKATKAN KUALITAS KEAGAMAAN MASYARAKAT DESA PALALANGAN
}

\author{
Sutriyono \\ Sekolah Tinggi Ilmu Syariah Darul Falah Bondowoso \\ email: sutriyono74dafa@gmail.com
}

\begin{abstract}
Abstrak
Masjid adalah sarana vital umat islam dalam menjalankan ibadah ritual keseharian, mingguan, dan tahunan. Masjid adalah simbol peradaban umat islam. Hakekatnya masjid dapat diperan fungsikan sebagai sarana sosial untuk menggerakkan, memberdayakan, dan meningkatkan kualitas masyarakat. Sakralitas masjid sebagai pusat tempat ibadah suatu kawasan menjadi magnet tersendiri dan dapat dijadikan sebagai modal dalam meningkatkan kualitas jamaah masjid melalui kegiatan-kegiatan yang bernuansa spiritual transendendal. Penelitian ini membahas tentang peran dan fungsi sosial masjid sebagai bagian dari sistem keagamaan dan pranata sosial. Jenis penelitian ini adalah field research dengan pendekatan kualitatif. Hasil penelitian menunjukkan bahwa masjid dapat menjalankan peran dan fungsi sosialnya dengan baik sebagai pusat kegiatan keagamaan masyarakat.
\end{abstract}

Kata kunci: peran, masjid, kualitas, keagamaan

\section{A. Pendahuluan}

Pendidikan merupakan sarana utama untuk merubah masyarakat suatu bangsa. Oleh karena itulah pendidikan berlangsung seumur hidup. Selama manusia hidup tetap mempunyai kewajiban belajar untuk meningkatkan kualitas dirinya melalui pendidikan dengan jalur formal, informal, dan non formal. Adanya berbagai jalur yang disediakan oleh pemerintah merujuk pada hak dasar asasi manusia dalam memperoleh pendidikan sesuai dengan kriteria umur pembelajar.

Masjid merupakan salah satu komponen umat islam dalam menjalankan ibadah wajib mingguannya yaitu shalat jumat. Masjid juga dipakai untuk kegiatan-kegiatan kegamaan penunjang ibadah wajib dalam rangka lebih mendekatkan diri kepada Allah 
Swt. yaitu kegiatan-kegiatan ibadah sunnah. Intinya masjid mempunyai peran dan fungsi yang vital dan menjadi pusat kegiatan keagamaan umat islam.

Pada perkembangannya masjid lebih berfokus semata-mata sebagai penyelenggara ritual keagamaan. Masjid ramai dikunjungi hanya pada saat-saat ritual besar keagamaan mingguan atau tahunan seperti bulan ramadhan atau peringatan-peringatan hari besar islam. Padahal masjid memiliki posisi sentral dalam menggerakkan masyarakat dalam isu-isu yang terkait dengan pembangunan kualitas spiritual, emosional, pengetahuan, sikap, dan keterampilan masyarakat dan bangsa.

Sekolah Tinggi Ilmu Syari'ah (STIS) Darul Falah Bondowoso sebagai salah satu lembaga perguruan tinggi islam yang mempunyai kewajiban melakukan syiar islam melalui penguatan keagamaan masyarakat sekitar dan penelitian dan pengabdian serta pemberdayaan masyarakat yang berorientasi peningkatan kualitas hidup masyarakat.

Kajian ini fokus pada peran dan fungsi masjid dalam meningkatkan kualitas SDM masyarakat Desa Plalangan Kecamatan Cermee Kabupaten Bondowoso tahun 2020 melalui pembinaan keagamaan agar memiliki ketahanan mental spriritual yang kuat. Maksud dari kata peran dan fungsi ini tidak merujuk pada struktur bangunan melainkan pada pengurus masjid dan masyarakat sekitar masjid dalam memanfaatkan fasilitas dan program kegiatan masjid. Penelitian ini merupakan field research dengan pendekatan kualitatif. Teknik pengumpulan data menggunakan wawancara, observasi, dan dokumentasi. Analisis data merujuk pada Miles dan Huberman. Sedangkan uji keabsahan datanya memakai trianggulasi data.

Masjid sebagai salah satu symbol dan syiar islam adalah bagian dari suatu unsur kebudayaan. Terlihat dari struktur dan bentuk ekterior dan interior masjid antara satu daerah dengan yang lainnya berbeda. Fleksibilitas bangunan masjid adalah nilai positif bagi islam itu sendiri. Bentuk masjid yang berbeda-beda mengindikasikan bahwa perbedaan dalam islam adalah suatu rahmat. Urgensi subtantif masjid adalah peran dan fungsinya sebagai pusat kebudayaan dan ritual umat islam dalam penguatan sistem nilai agama. Kontjaraningrat (1980) mengatakan bahwa sistem agama (religi) termasuk dalam unsur kebudayaan. Sebagai salah satu unsur kebudayaan manusia peran dan fungsi masjid harus selaras dengan perkembangan sistem sosial dan budaya manusia. Masjid merupakan salah satu indikator maju mudurnya kebudayaan manusia dengan segala varian ritualitas kegamaannya. Sehingga masjid menjadi unsur penting dalam 
sistem sosial yang religious. A. Bachrun Rifai (2005) menyebut masjid sebagai pranata sosial yang memenuhi kebutuhan dasar manusia. Salah satu dari kebutuhan dasar manusia adalah spiritualitas.

Sudah menjadi tuntutan perkembangan zaman bahwa masjid harus difungsikan dalam berbagai kegiatan sosial keagamaan yang menunjang kemajuan umat islam dari berbagai aspeknya. Nada pesimis diutarakan oleh Sidi Gazalba (1989) bahwa bukan tidak mungkin umat islam akan mengalami kemunduran bila masjid hanya difungsikan sebagai tempat shalat saja.

Konsep memakmurkan masjid tidak sebatas batas ramai ibadah dalam masjid akan tetapi masjid beserta pengurus takmir mampu menjalankan peran dan fungsinya sebagai bagian dari media syiar islam melalui peningkatan kualitas masyarakat sekitar masjid.

\section{B. Pembahasan}

1. Profil Desa

a. Sejarah Desa Plalangan

Puluhan tahun yang lalu Plalangan adalah bagian dari Desa Ramban Kulon, yang mayoritas Penduduknya adalah Suku Madura. Namun, karena Plalangan merupakan Daerah terpencil dan sulit di jangkau untuk memperoleh pelayanan secara maksimal oleh Pemerintahan Desa induk, Maka Plalangan menjadi Desa yg sangat tertinggal dan terisolasi dari perhatian Pemerintah.

Waktu terus berjalan dari satu pemimpin ke pemimpin lain dan fase Orde Baru Plalangan tetap menjadi Desa yang tertinggal, sehingga datanglah suatu zaman yg disebut Orde Reformasi, melalui Tokoh Ulama' dan tokoh Masyarakat Plalangan mencoba untuk merubah nasib dengan upaya meminta pemekaran Desa pada tahun 2006.

Selanjutnya melalui tokoh KH. Abd. Qadir Syam dan KH. Mahfud Ahmadi Syam serta kepala Desa induk (H. Herzul Arifin) berkumpul untuk membahas rencana pemekaran Desa dan dalam acara tersebut hadir pula Kepala Wilayah Kecamatan Cermee (Bpk. Jahrawi) serta tokoh-tokoh Dukuh Plalangan yang bertempat di rumah H. Ibnu Mas'ud. Kegiatan tersebut akhirnya sepakat untuk bersama-sama memohon kepada Pemerintah Kabupaten untuk membentuk Desa Pemekaran dengan Nama Desa Plalangan. Nama Plalangan sendiri diperoleh dari cerita sesepuh yang menuturkan bahwa dahulu kala Plalangan merupakan daerah yang dipenuhi oleh tumbuhan Ilalang. Musyawarah 
tersebut menghasilkan aklamasi bahwa H. Ibnu Mas'ud diusulkan sebagai Pejabat sementara Kepala Desa sampai proses Pemilihan secara Demokratis dilaksanakan.

Pada awal tahun 2007 tepatnya 31 Maret 2007 harapan dan impian Masyarakat Plalangan menjadi sebuah kenyataan karena mulai saat itulah Plalangan resmi menjadi Desa pemekaran dengan status Desa Persiapan dan sekaligus dilantik saudara H. Ibnu Mas'ud menjadi Pejabat sementara oleh Bupati Bondowoso.

Kisah lain disebutkan bahwa nama Plalangan diambil dari asal mula sesepuh terdahulu dalam mengadu nasib untuk menyambung hidup dengan cara menjual Ilalang ke Desa tetangga yang secara kebetulan pula daerah ini cukup lebat dengan rumput Ilalang.

Desa Plalangan terbagi menjadi 6 (enam) Dusun yakni Dusun Krajan I, Dusun Krajan II, Dusun Batu Langgar, Dusun Sappar, Dusun Gundang dn Dusun Congkeng b. Struktur Organisasi Pemerintah Desa

Susunan Organisasi Pemerintah Desa terdiri dari Kepala Desa dan Perangkat Desa yaitu Sekretaris Desa, Pelaksana Teknis Lapangan dan Unsur kewilayahan. Kepala Desa 1 orang, Perangkat Desa Sekretaris Desa 1 orang, Bidang Urusan 3 orang, Pelaksana Teknis 3 orang dan Pelaksana kewilayahan 6 orang.

Secara umum pelayanan pemerintah Desa Plalangan kepada masyarakat cukup memuaskan. Dalam beberapa sesi wawancara langsung dengan masyarakat Desa Plalangan yang dipilih secara acak, terungkap bahwa dalam memberikan pelayanan pengurusan administrasi kependudukan, pertanahan dan lain-lain dikerjakan dengan cepat dan dilayani selama 24 jam, baik pelayanan pada jam kerja di kantor maupun di luar jam kerja di rumah kepala desa, sekretaris desa atau perangkat desa lainnya.

c. Demografi

Desa Plalangan dengan luas wilayah 840 ha merupakan salah satu desa di Kecamatan Cermee Kabupaten Bondowoso.

Batas wilayah Desa Plalangan :

O

$\bigcirc$

○

○ Sebelah Barat

Sebelah utara

Sebelah selatan

Sebelah Timur

\section{: Desa Ramban Kulon Kecamatan Cermee \\ : Desa Jirek Mas Kecamatan Cermee \\ : Desa Ramban Wetan Kecamatan Cermee}

Topografi dengan bentang wilayah berombak sampai berbukit.

○ Curah hujan $\quad: 134,00 \mathrm{~mm}$ 
$\circ \quad$ Jumlah bulan hujan : 5 bulan

- Suhu rata-rata harian $: 37^{\circ} \mathrm{C}$

○ Tinggi tempat $\quad: 158 \mathrm{~m} \mathrm{dpl}$.

Luas wilayah Desa Plalangan 840 Ha. terdiri dari:

$\begin{array}{lll}\text { Tanah sawah } & : & 50 \mathrm{Ha} \\ \text { Tanah Kering (tegal) } & : & 530 \mathrm{Ha} \\ \text { Permukiman } & : & 160 \mathrm{Ha} \\ \text { Tanah Hutan lindung } & : & 100 \mathrm{Ha} \\ \text { adaan Sosial Budaya } & & \\ \text { pendudukan } & & \end{array}$

Berdasarkan Data Administrasi Pemerintah Desa, jumlah penduduk yang tercatat secara administrasi, jumlah total 2153 jiwa. Dengan rincian penduduk berjenis kelamin lakilaki berjumlah 1046 jiwa, sedangkan berjenis kelamin perempuan berjumlah 1107 jiwa. Berkaitan dengan data jumlah penduduk dapat dilihat pada Tabel 1.1 berikut ini :

Tabel 1.1. Jumlah Penduduk Berdasarkan Jenis Kelamin Desa Plalangan Tahun 2019

\begin{tabular}{|l|l|l|l|}
\hline No. & Jenis Kelamin & Jumlah & Persentase (\%) \\
\hline & Laki-laki & 988 & $45 \%$ \\
\hline & Perempuan & 1.165 & $55 \%$ \\
\hline & Jumlah & 2.153 & $100 \%$ \\
\hline
\end{tabular}

Sumber : Profil Desa Plalangan Kecamatan Cermee, Tahun 2019

Keadaan kependudukan di Desa Plalangan dilakukan identifikasi jumlah penduduk dengan menitikberatkan pada klasifikasi usia dan jenis kelamin. Untuk memperoleh informasi yang berkaitan dengan deskripsi tentang jumlah penduduk di Desa Plalangan berdasarkan usia dan jenis kelamin secara detail dapat dilihat berikut ini; 
Tabel 1.2 .Jumlah Penduduk Berdasarkan Kelompok Usia Desa Plalangan Tahun 2019

\begin{tabular}{|l|l|l|l|l|l|}
\hline No. & Kelompok Usia & $\begin{array}{l}\text { Laki- } \\
\text { laki }\end{array}$ & Perempuan & Jumlah & Persentase (\%) \\
\hline & $0-6$ & 180 & 200 & 380 & $18 \%$ \\
\hline & $7-15$ & 201 & 212 & 413 & $19 \%$ \\
\hline & $16-18$ & 111 & 161 & 272 & $13 \%$ \\
\hline & $19-24$ & 125 & 155 & 280 & $13 \%$ \\
\hline & $25-39$ & 122 & 135 & 257 & $12 \%$ \\
\hline & $40-49$ & 90 & 120 & 210 & $10 \%$ \\
\hline & $50-59$ & 70 & 82 & 152 & $7 \%$ \\
\hline & Jumlah & 988 & 1165 & 189 & $8 \%$ \\
\hline
\end{tabular}

Sumber : Data UPTD PP dan KB Kecamatan Cerme Tahun 2019

Dari total jumlah penduduk Desa Plalangan, yang dapat dikategorikan kelompok rentan dari sisi kesehatan mengingat usia, yaitu penduduk yang berusia $>56$ tahun. Jumlah yang paling banyak $8 \%$ adalah antara usia 60 sampai dengan 75 . Sementara jumlah penduduk usia produktif yaitu dari usia 19-59 tahun sejumlah $42 \%$.

Dari usia $>60$ tahun tersebut jumlah penduduk berjenis kelamin laki-laki sebanyak $4 \%$ dan perempuan ada $4 \%$. Sedang pada usia 0-4 tahun, yang berjenis kelamin laki-laki 8 $\%$ dan perempuan $10 \%$.

Penduduk usia produktif pada usia antara 19-59 tahun di Desa Plalangan jumlahnya cukup signifikan, yaitu 899 jiwa atau $41 \%$ dari total jumlah penduduk. Terdiri dari jenis kelamin laki-laki $19 \%$, sedangkan perempuan $23 \%$.

Dari data tersebut diketahui bahwa jumlah laki-laki/wanita usia produktif lebih banyak. Dengan demikian sebenarnya perempuan usia produktif di Desa Plalangan dapat menjadi tenaga produktif yang cukup signifikan untuk mengembangkan usaha-usaha produktif diharapkan semakin memperkuat ekonomi masyarakat, sementara ini masih bertumpu kepada tenaga produktif dari pihak laki-laki.

2) Mata pencaharian Pokok

Secara umum mata pencaharian warga masyarakat Desa Plalangan dapat teridentifikasi ke dalam beberapa bidang mata pencaharian, seperti petani, buruh tani, pedagang, 
wiraswasta, buruh bangunan/tukang, peternak. Jumlah penduduk berdasarkan mata pencaharian dapat dilihat pada tabel 1.3.

Berdasarkan tabulasi data tersebut teridentifikasi, di Desa Plalangan jumlah penduduk yang mempunyai mata pencaharian ada $42 \%$. Dari jumlah tersebut, kehidupannya bergantung di sektor pertanian, ada $49 \%$ dari total jumlah penduduk.

Jumlah ini terdiri dari buruh tani terbanyak, dengan 671 dari jumlah penduduk yang mempunyai pekerjaan atau $31 \%$ dari total jumlah penduduk. Petani sebanyak 325 dari jumlah penduduk yang mempunyai pekerjaan atau $15 \%$ dari total jumlah penduduk.

Terbanyak ketiga adalah 937 dengan $43 \%$ dari jumlah penduduk yang mempunyai pekerjaan. Sementara penduduk yang lain mempunyai mata pencaharian yang berbedabeda, ada yang berprofesi sebagai, pedagang, sopir, wiraswasta, tukang bangunan, dan lain-lain.

Tabel 1.3. Jumlah Penduduk Menurut Mata Pencaharian Desa Plalangan Tahun 2019

\begin{tabular}{|l|l|l|l|}
\hline No. & Jenis Pekerjaan & Jumlah & $\begin{array}{l}\text { Total Jumlah } \\
\text { Penduduk (\%) }\end{array}$ \\
\hline & Petani & 325 & $15 \%$ \\
\hline & Buruh tani & 671 & $31 \%$ \\
\hline & PNS/TNI/POLRI & 3 & $01 \%$ \\
\hline & Karyawan swasta & - & - \\
\hline & Wedagang & 87 & $4 \%$ \\
\hline & Pensiunan & 2 & $09 \%$ \\
\hline & Tukang bangunan & 35 & - \\
\hline & Peternak & - & - \\
\hline & Lain-lain/tidak tetap & 228 & $10 \%$ \\
\hline & Jumlah & 1287 & $30 \%$ \\
\hline
\end{tabular}

Sumber : Dari Profil Desa Plalangan, Juni 2019

Dengan demikian dari data tersebut menunjukkan bahwa warga masyarakat di Desa Plalangan memiliki alternatif pekerjaan selain sektor buruh tani dan petani. Setidaknya karena kondisi lahan pertanian mereka sangat tergantung dengan curah hujan alami. Di sisi lain, air irigasi yang ada tidak dapat mencukupi untuk kebutuhan lahan pertanian di 
Desa Plalangan secara keseluruhan terutama ketika musim kemarau. Sehingga mereka pun dituntut untuk mencari alternatif pekerjaan lain.

3) Kondisi Kesehatan

a) Kesehatan adalah salah satu anugerah yang harus di jaga, demikian juga dengan kondisi kesehatan yang ada di desa Plalangan, salah satu pelayanan kesehatan terdekat adalah Bidan Desa dan Polindes, saat ini Polindes masih menempati balai desa. Puskesmas Cermee yang melayani kesehatan setiap hari.

b) Posyandu sebagai salah satu program bidang kesehatan tentunya sangat dibutuhkan oleh masyarakat desa, khususnya desa Plalangan, sehingga kegiatankegiatan terkait dengan posyandu sangat diperhatikan oleh pemerintah desa Plalangan. Terdapat 4 (empat) Posyandu di desa Plalangan, di antaranya adalah Nusa Indah I, Nusa Indah II, Nusa Indah III, Nusa Indah IV. Adapun kegiaatan rutin yang menjadi programnya adalah, pemeriksaan ibu hamil dan menyusui, pemeriksaan lansia, pemberian makanan tambahan anak usia sekolah, penyuluhan program keluarga berencana ( KB ) dan penyuluhan sadar kesehatan.

c) Untuk ketersediaan air bersih, pemerintah desa Plalangan masih belum mampu mencukupi ketersediaan air berskala desa, dari 881 jumlah kepala keluarga (KK) hanya mampu mencukupi sekitar 300 KK. Kondisi ini disebabkan oleh sarana minimnya pipanisasi yang belum cukup untuk menghubungkan ke seluruh kepala keluarga (KK) di desa Plalangan.

d) Sedangkan untuk kepemilikan jamban, dari total 881 kepala keluarga (KK) hanya berkisar 400 kepala keluarga yang memiliki jamban.

4) Pendidikan

Pendidikan adalah satu hal penting dalam memajukan tingkat kesejahteraan dan tingkat perekonomian. Dengan tingkat pendidikan yang tinggi maka akan mendongkrak tingkat ketrampilan. Tingkat ketrampilan juga akan mendorong tumbuhnya ketrampilan kewirausahaan. Dan pada gilirannya mendorong munculnya lapangan pekerjaan baru sehingga akan membantu program pemerintah untuk pembukaan lapangan kerja baru guna mengatasi pengangguran. Data berikut menunjukkan tingkat rata-rata pendidikan warga Desa Plalangan yakni belum sekolah 126 orang, pernah sekolah SD tapi tidak tamat 68 orang, tamat SD / sederajat 513 orang, tamat SLTP / sederajad 225 orang, 
tamat D2 7 orang, tamat S1 25 orang, jumlah Sekolah TK 3 unit, jumlah lembaga PAUD 2 unit, jumlah sekolah SD / sederajad 3 unit.

Berdasarkan data kualitatif yang diperoleh menunjukkan bahwa di Desa Plalangan kebanyakan penduduk usia produktif hanya memiliki bekal pendidikan formal pada level pendidikan dasar $23 \%$ dan pendidikan menengah - SLTP dan SLTA - $10 \%$. Sementara yang dapat menikmati pendidikan di Perguruan Tinggi hanya $1 \%$. Dan terdapat 68 jiwa atau $3 \%$ tidak tamat SD.

5) Kondisi Ekonomi dan Kemampuan Fiskal Desa

Pendapatan Desa Plalangan selama ini bersumber dari penerimaan Asli Desa ( PADes ), penerimaan yang berasal dari Pemerintah Pusat, dan Bantuan Provinsi atau kabupaten 2. Profil Masjid

Desa Plalangan mempunyai tiga masjid sebagaimana berikut;

a. Masjid Darul Huda

Masjid Darul Huda adalah masjid yang di dirikan pada tahun 1960 M, yang terbuat dari bangunan sederhana. Pendiri pertama yaitu KH. Syamsuri atas petunjuk KH.Syamsul Arifin (Pengasuh Pondok Pesantren Darul Falah, Ramban Kulon) dan KH. Hasan (Pengasuh Pondok Pesantren Nangkaan). Tanah yang di bangun untuk masjid yaitu milik pribadi oleh KH. Syamsuri.

Peta lokasi pembangunan lokasi masjid pada tahun 1960 M, berada di desa Plalangan dengan luas $(8.8=64 \mathrm{~m}$ ). Pada tahun 1995 Masjid Darul Huda di rehat dan di luaskan menjadi (14 . $14 \mathrm{~m}$ ) dengan lokasi keseluruhan $3750 \mathrm{~m}$. Visi masjid adalah “Terwujudnya masyarakat yang beriman dan beraqidah Ahlus Sunnahwaljamaah". Misi masjid ini adalah mengamalkan syari'at dengan mengikuti salah satu 4 madzhab, memakmurkan masjid untuk mempermudah santri dan masyarakat agar memperoleh pendidikan keagamaan, dan melaksanakan proses belajar mengajar berbasis keagamaan.

Adapun struktur pengurus masjid sebagai berikut;
1)
Pelindung
: Kepala Desa
2) Pendiri
: KH. Syamsuri
3) Penasehat / Pengasuh : K. Abdur Rosyid
4)
Ketua
: H. Ibnu Mas'ud
5)
Sekretaris
: Ust. Syafi' 'i
6)
Bendahara
: Ahmad Syahri 
Seksi-seksi

Muadzin

: As'yari dan Siman

Bilal

: H. Hidayat dan Kholil

Khotib

: Abdur Rosyid, H.Ibnu Mas'ud, Ust. Syafi'I, Ust. Moh

Shaleh,dan Ust. Anis

Struktur Remas ;

1) Ketua

2) Sekretaris

3) Bendahara

4) Seksi-seksi
: Qomaruddin

: Baihaki

: Amir Mahmud

: Abd. Qodir

Anggota

: Hadi, Syafi'I, Rafi'i, dan Sulaiman

b. Masjid Nurul Hikmah

Masjid Nurul Hikmah desa Plalangan kecamatan cermee kabupaten bondowoso.derdiri sejak tahun 1970 oleh masyarakat Plalangan.

Masjid Nurul Hikmah dibangun oleh masyarakat Plalangan di atas tanah milik sendiri [pribadi] oleh kyai Jannatun seluas $448 \mathrm{~m}$.

Bentuk fisik masjid nurul hikmah berukuran panjang $10 \mathrm{~m}$, lebar $10 \mathrm{~m}$, bangunan serambi masjid $10 \mathrm{~m}$ termasuk mihrab kemudian secara terpisah di bangun tempat wudlu' dan kamar mandi berukuran panjang $5 \mathrm{~m}$ dan lebar $3 \mathrm{~m}$, ini termasuk keseluruhan bangunan masjid nurul hikmah.

Visi dan misi masjid Masjid Nurul Hikmah yaitu menjadikan masjid sebagai tempat ibadah, wadah umat Islam serta menjunjung tinggi nilai-nilai ke-Islaman dan membentuk generasi mudah yang selaalu akan ingin dengan masjid. Misinya adalah menjadikan masjid yang selalu Imaroh, Idaroh Dar Riayah serta selalu berperan aktif dalam kehidupan masyarakat sekarang dan masa yang akan datang.

Tujuan di dirikan Masjid Nurul Hikmah Desa Plalangan kecamatan Cermee Kabupaten Bondowoso yaitu agar masyarakat Islam akan mudah dalam menjalankan ibadah yang wajib maupun sunnah. Kemudian dengan adanya masjid, maka umat Islam akan selalu bersatu dan terjaga persaudaraan atau tali silaturrahmi antar umat Islam.

Struktur pengurus masjid Nurul Hikmah sebagai berikut;
1) Pelindung
: Kepala desa
2) Penasehat
: H. Ismail Abdullah 
3) Ketua

4) Sekretaris

5) Bendahara
: Abd Latif

: Saiful Rauf

: H. Mahmud

Seksi- seksi

Humas

Kebersihan

Perlengkapan

Imam dan Khotib

Struktur Remas

Ketua

Sekretaris

Bendahara
: Ma'ruf

: Sattawi

: Firdaus

: Abd. Latif, H. Mahmud, Abdullah

: Saifur Rauf

: Makruf

: Muhsin

\section{Seksi- Seksi}

Bidang dakwah

: H. hasan dan Eksan

Bidang Pendidikan

: Abdullah dan Ikam Maulana

Bidang Sosial

: Zainullah dan Ahmad

Bidang Kesenian

: Ahmad Fiqih dan Mukhlisin

c. Masjid Miftahul Hidayah

Masjid Miftahul Hidayah yaitu berdiri sejak tahun 1987 M. Konon, pada awalnya tanah tersebut yaitu tanah pemberian (Hibbah), yang diberikan oleh kakek dari pada $\mathrm{K}$. Masyhuri (Penasehat:sekarang) dan pada awalnnya masjid tersebut berstatus Mushollah biasa dan sederhana.

Masjid yang berubah menjadi mushollah di karenakan adanya intruksi dari salah satu Tokoh agama yang berkunjung ke mushollah tersebut yaitu KH. Syamsul Arifin dan KH. Hannan . Alasan dari pada itu yaitu agar jamaah bertambah lebih banyak.Dan kini masjid tersebut berkembang pesat sehingga membangun madrasah diniyah untuk menampung anak-anak dalam kegiatan pembelajaran agama.

Struktur organisasi kepengurusan masjid adalah sebagai berikut;
1) Pelindung
: KH. Hasyim
2) Penasehat
: K. Masyhuri
3) Ketua
: Nimbeng
4) Sekretaris
: Rawito 
5) Bendahara

: Abd Rahman

Seksi-seksi

Kebersihan

Humas

Perlengkapan

Pembangunan

Khotib, Bilal dan Mu' adzin

Khotib

Bilal

Mua'adzin

Struktur remas
: Khoiriyah, Toyani, Matriju, Hartodik

: Muhaki, Misrawi, Tohari, Madroso

: Nur, Tomo, Sariyanto, Nur Hani

: Bakir, Hosen, Mustaqim

: K.Masyhuri , KH.Hasyim

: M.Gazeli, Nihari

: Wahyudi, Shomadin, Toyib, S Bahri

Ketua

: Muhammad Ilyas

Anggota

: Reki Mawarda, Muhammad Kholil, Ahmad Zubaidi,

Syamsul Arifin, Sawiyanto, Toyyib

3. Kondisi Sosial Ekonomi dan Keagamaan

a. Masjid Darul Huda

Kondisi sosial ekonomi masyarakat sekitar Masjid Darul Huda Desa Plalangan Kecamatan Cermee Kabupaten Bondowoso rata-rata termasuk dalam kategori keluarga sejahtera sebagian besar masyarakatnya seorang petani dan berkebun (kunyit). Interaksi warga masih belum intens dan kurang bersatu dalam berbagai kegiatan serta nilai sosial di dalamnya masih kurang rasa kebersamaan (solidaritas) yang kurang baik.

Adapun kegiatan keagamaan yang berlangsung di Masjid Darul Huda yaitu:

1) Sholawat Nariyah 1 minggu sekali

Kegiatan ini dilakuakan setiap malam kamis dengan jumlah jamaah sekitar 30 orang.isi kegiatan membaca sholawat nariyah 4444 sekaligus tahlil dan dilanjutkan dengan sholat isya' berjamaah.

2) Sholawat Nariyah 1 bulan sekali

Kegiatan ini d lakukan setiap 1 bulan sekali tepatnya hari rabu terakhir.di hadiri oleh ketua muslimat MWC NU Bondowoso beserta keluarga Darul Falah.Isi kegiatannya membaca sholawat nariyah 4444 .

3) Khotmil Qur'an 
Kegiatan dilakukan 1 bulan sekali dengan kegiatan utamanya khotmil qur'an yang dilaksanakan oleh tahfidz Darul Falah.yang di dalamnya terdapat kas arwah.

b. Masjid Nurul Hikmah

Masyarakat sekiatar Masjid Nurul Hikmah Dusun Muncel dari segi ekonomi rata-rata keluarga sejahtera.Warga lingkungan sekitar sangat antusias dalam berorganisasi dan berinteraksinya baik. Nilai sosialnya sangat tinggi, kompak dan peduli dalam lingkungan warga dusun Muncel.

a. Kondisi Keagamaan

Adapun kegiatan keagamaan yang berlangsung di Masjid Miftahul Hidayah yaitu:

1) Kegiatan Istighasah setiap malam Selasa

(Wawancara: 6 Maret 2020)

2) Kegiatan Sholawat Nariyah setiap malam Kamis

(Wawancara:6 Maret 2020)

c. Masjid Miftahul Hidayah

Di tinjau dari segi ekonomi masyarakat sekitar masjid Miftahul Hidayah yaitu termasuk pada kelas menengah keatas.Karena kemajuan teknologi mesin, sehingga ekonomi masyarakat sudah meningkat.Hasil ekonomi yang diperoleh yakni dari hasil tani masyarakat. Seperti, padi, jagung, cabe, tomat dan lain lain.

Adapun kegiatan keagamaan yang terlaksana di Masjid Miftahul Hidayah yaitu:

1) Sholawat nariyah yang di laksanakan dengan rutin setiap malam rabu dengan anggota muslimin dan muslimat.

2) Arisan istighasah, yang di laksanakan setiap hari jum'at sekitar jam 1 siang. Anggota dari pada kegiatan ini yaitu muslimat.

3) Arisan Nariyaan, yang di laksanakan setiap malam jum'at oleh muslimin.

4) Kegiatan PHBI ( Isra' Mi'raj ) yang biasanya di laksanakan bersamaan dengan imtihan.

\section{Penguatan Keagamaan Masyarakat}

Masyarakat Plalangan masih minim akan kajian keagamaan, maka takmir masjid di Plalangan mengadakan kegiatan keagamaan yang melibatkan muslimin dan muslimat di dalamnya. Program-program kegiatan masjid untuk meningkatkan yakni

a. Pelatihan Tajhizul Jenazah 
Tempat kegiatan ini berlangsung di Masjid Darul Huda krajan 1 RT 05 Plalangan.Pelaksanaanya sekitar jam 12:30.Sasarannya Warga Palangan. Tujuan Program menambah wawasan masyrakat terkait dan merawat Jenazah yang baik dan benar. Bahan yang diperlukan dalam kegiatan ini buku pedoman tajhizul jenazah,Kain Kafan,kapas,sampir,dan lain-lain.

Pelaksanaan dari Kegiatan tajhizul jenazah yang diadakan di Krajan 2 Plalangan masih terliat belum kompak karena terkait waktu bekerja masyarakat di siang hari.

Hasil dan Manfaat Warga masyarakat yang mayoritas masih awam dan hanya ada salah satu yang bisa merawat jenazah di satu lingkungan,sekarang sudah mulai paham cara merawat jenazah yang baik dan benar.Bahkan masyarakat menginginkan pelatihan merawat jenazah diadakan kembali.

\section{b. Fiqih Wanita}

Tempat kegiatan ini di Masjid Miftahul Hidayah krajan 1 RT 02 Plalangan.Sasaran Muslimat krajan 1 RT 02 Plalangan.Tujuan dari Program ini Untuk mengetahui lebih luas kajian tentang fiqih wanita dan menjawab ketidakpahaman masyarakat mengenai Haid.Bahan yang diperlukan dari kegiatan ini buku Pedoman dan ringkasan fiqih.

Pelaksanaan kegiatan ini berjalan dengan lancar,warga terliihat antusias dan datang lebih awal sebelum pemateri hadir.

Hasil dan Manfaat dari kajian fiqih wanita yaitu masyarakat lebih memahami seputar haid dan mampu menerapkannya dalam kehidupan sehari-hari.Karena sebagian masyarakat awam dan masih menyepelekan hukum-hukum tentang haid.

c. Fiqih Munakahat dan Kesehatan Reproduksi

Tempat dari kegiatan ini di Masjid Nurul Hikmah Muncel RT 09 Plalangan.Waktu pelaksanaan sekitar jam 18:30.Sasaran dari kegiatan ini adalah Warga Muncel RT 09 Plalangan.

Tujuan Program ini memperdalam kajian fiqih munakahat terkait hukum-hukum pernikahan dan hubungannya dengan kesehatan reproduksi.Dan tercipta keluarga sakinah,mawaddah dan warahmah.Selain itu membutuhkan bahan yaitu Buku pedoman seputar Fiqih Munakahat dan kesehatan reproduksi.

Pelaksanaan Kegiatan ini berjalan dengan baik, warga Dusun Muncel sangat antusias dalam mengikuti kajian tersebut dimulai dari sholat maghrib berjamaah sampai isya' berjamaah warga Dusun Muncel masih antusias sampai menunggu pemateri datang. 
Hasil dan Manfaat dari kegiatan ini Warga mengetahui lebih luas tentang Fiqih munakahat dalam hukum-hukum keluarga yang dikaitkan dengan kesehatan reproduksi. d. Isra' Mi'raj

Tujuannya untuk menambah keimanan kita dan selalu mengingat kejadian bersejarah dalam islam.Adapun Hasil dan manfaat Masyarakat antusias dan kompak dalam merayakan kegiatan isra' mi'raj ini dan selalu mengingat hari-hari bersejarah lainnya selain isra'mi'raj.

e. Khotmil Quran

Kegiatan ini dilalukan di tiga Masjid di Plalangan,yaitu di Masjid Darul Huda,Masjid Miftahul Hidayah dan Masjid Nurul Hikmah.apaelaksanaannya dilaksanakan setiap hari minggu jam 08:00.Bersama ibu muslimat setempat.

Tujuan dalam kegiatan ini menjadikan masyarakat terus mencintai al quran dan selalu membacanya setiap waktu. Hasil dan manfaat dari kegiatan ini masyarakat mulai rutin membaca Alquran setiap minggunya dan lancar dalam membacanya.

f. Pembacaan Rotibul Haddad dan Istighasah

Tujuan dilaksanakannya kegiatan ini agar masyarakat dan santri terbiasa membaca rotibul haddad dan istighasah dan setiap waktu asar. Hasil dan manfaat dari kegiatan adalah masyarakat mempunyai kecerdasan spiritual emosional.

g. Praktek Sholat dan Bimbingan belajar Alquran

Tujuan dari Program ini menjadikan santri menguasai dalam pembacaan Al quran dan sholat yang benar secara islam. Hasil dan manfaat dari kegiatan ini santri lebih lancar dalam pembacaan Alquran dan gerakan sholatnya lebih sempurna.

h. Pendidikan Madrasah Diniyah

Tujuan dari kegiatan ini mengajar santri dan menjadikan santri mampu memahami ilmu agama. Hasil dan manfaat dari kegiatan ini santri menjadi generasi masa depan desa yang paham dan terampil dalam bidang keagamaan.

\section{Faktor Pendukung dan Penghambat}

Masjid dalam menjalankan peran dan fungsinya sebagai fasilitas umat islam dalam membumikan nilai-nilai islam tidak lepas dari faktor pendukung dan penghambat.

1. Faktor Pendukung 
a. Kepala desa memberikan dukungan penuh baik material dan pemikiran dalam kegiatan keagamaan masjid, aktif mengajak perangkat desa dan warga untuk terlibat dalam acara keagamaan yang dilakukan masjid.

b. Perangkat Desa melayani dan memfasilitasi dalam mencetak berbagai dokumen seperti undangan dan fasilitas kegiatan lainnya.

c. Ketua Fatayat dan Ketua Muslimat Desa Plalangan membantu kelancaran kegiatan keagamaan masjid dan meluangkan waktu untuk menghadiri kegiatan dan mengajak masyarakat untuk berpartisipasi dalam acara.

2. Faktor Penghambat

Ada beberapa hambatan dalam pelaksanaan penguatan spiritualitas keagamaan masjid.

a. Pembiayaan. Pembiayaan kegiatan keagamaan yang digagas masjid tidak sepenuhnya bersumber dari keuangan masjid karena keterbatasan dana masjid.

b. Tingkat kehadiran masyarakat di siang hari lebih sedikit dibandingkan kegiatan yang dilaksanakan malam hari karena masyarakat bekerja di sawah.

\section{Kesimpulan}

1. Masjid di desa Plalangan mampu menjalankan peran dan fungsinya dengan baik sebagai fasiltas agama dalam penguatan spiritualitas masyarakat melalui programprogram keagiatan keagamaan harian, mingguan, bulanan, dan tahunan.

2. Masjid sebagai fasilitas umat islam dalam menjalankan peran dan fungsi melalui program-program keagamaan mampu berisinergi dengan pihak pemerintah dan organisasi sosial kemasyarakatan. 


\section{Daftar Pustaka}

Gazalba, Sidi. Masjid Pusat Ibadah dan Kebudayaan Islam, Jakarta Pustaka Al-Husna, 1989.

Koentjaraningrat. Pengantar Ilmu Antropologi, Jakarta, Aksara Baru, 1980.

Miles, M.B., and Huberman, A.M., (1994), Qualitatif data analysis, second edition, Sage Publications International Educational and Professional Publisher, Thousand Oaks London New Delhi

Nawawi, Hadari. Metode Penelitian Bidang Sosial, Yogyakarta: Gajah Mada University Press, 1995.

Rifai, A.Bachrun. Manajemen Masjid Mengoptimalkan Fungsi Sosial-Ekonomi Masjid, Benang Merah Pres.2005.

Uhar, Suharsaputra. Metodologi Penelitian Kuantitatif, Kualitatif, dan Tindakan, Bandung: Refika Aditama, 2012. 